\title{
PROGRAMAS TELEVISIVOS: RELATO DE PRE ESCOLARES
}

\section{TELEVISION PROGRAMS: PRE-SCHOOL CHILDREN REPORTS}

\author{
Yumi Gosso ${ }^{1}$ \\ Celina Maria Colino Magalhães ${ }^{2}$ \\ Fernando Augusto Ramos Pontes ${ }^{3}$
}

GOSSO, Y.; MAGALHAES, C. M. C.; PONTES, F. A. R. Programas Televisivos: Relato de Pré-Escolares. Rev. Bras. Cresc. Desenv. Hum., São Paulo, 8 (1/2), 1998.

\begin{abstract}
Resumo: Há evidências de efeitos negativos da programação televisiva com cenas de violência no comportamento das crianças, sendo importante portanto, verificar o que elas estão relendo dos programas que assistem. Assim, investigou-se o ponto de vista do telespectador infantil sobre os programas televisivos. Para isso, utilizou-se um questionário e realizou-se entrevistas individuais a 350 crianças com idade entre cinco e seis anos das classes sócio-econômica baixa (160) e classe média (190). Os resultados indicaram que os episódios agressivos estão entre os preferidos das crianças de ambos os sexos e grupos sociais e observou-se também que as crianças de classe baixa têm dificuldade de fazer relatos verbais. Este panorama demonstra que há necessidade de monitoramento dos adultos em relação à programação assistida pelas crianças e que talvez a metodologia utilizada possa ter favorecido as crianças de classe média em detrimento das de classe baixa.
\end{abstract}

Palavras-chave: pré-escolares; programas televisivos; agressividade.

Atualmente, a televisão se apresenta como um dos mais poderosos agentes que influenciam e aluam direta ou indiretamente sobre o desenvolvimento infantil. Isto ocorre em função da criança estar cada vez mais distante das brincadeiras com seus coetâneos e ter forte tendência a imitar personagens de seus programas prediletos, podendo assumir o papel de alguns desses personagens.

Segundo uma pesquisa realizada nos Estados Unidos ("Good Television Habits”, sem data), uma criança que começa a frequentar a escola já assistiu uma média de 4.000 horas de programas televisivos. Conforme os resultados dessa pesquisa, muitas horas diante de um aparelho de televisão podem ser prejudiciais à criança devido aos seguintes fatores: a) a criança pode ficar exposta a cenas de muito sexo e violência; b) a influência indevida de alimentos inadequados e de comerciais de brinquedos; c) maus exemplos de modelos de comportamento antes da criança ter esclarecido o conceito do que é certo ou errado; d) a criança não possui experiência e nem bom senso suficiente para compreender as cenas complexas e de terror; e) ao ficar passivamente por um longo tempo diante da televisão pode atrasar o desenvolvimento sócio-intelectual da cnança.

1 Mestranda do Curso de Psicologia: Teoria e Pesquisa do Comportamento da Universidade Federal do Pará e bolsista da CAPES. End. Caixa Postal 158, Centro, Belém - PA - CEP 66.017-970. Tel/fax: (091) 211-1662.

E-mail: gosso@interconect.com.br

2 Professores Doutores do Departamento de Psicologia Experimental da Universidade Federal do Pará. 
Além do conteúdo dos programas em si, existem também os comerciais, propagandas exibidas na televisão durante os intevalos das programaçoes. E importante lembrar das propagandas porque crianças muito pequenas não conseguem diferenciar os comerciais dos programas e acabam pensando que tudo faz parte de uma mesma programação.

Há evidências de que a constante exposição a programas inadequados à criança, tais como cenas de violência, está correlacionada com os comportamentos de discutir, entrar em conflito com os pais. ou até de cometer aios delituosos, ou seja, quanto maior a exposição a cenas de violência, maior a agressividade da criança (MOSER, 1991). Um experimento com dois grupos de crianças, um exposto diariamente a programas agressivos e o outro a programas de viagens sem violência indicou que quando após a essa exposição as crianças realizavam atividades livres, o grupo exposto a programas agressivos apresentou maior agressividade do que as demais crianças (MUS-SEN, CONGER, KAGAN \& HUSTON, 1938).

Uma pesquisa realizada por LEYENS (citado por MOSER, 1991), mostrou também que jovens delinquentes expostos a filmes violentos durante uma semana, apresentavam comprometimentos agressivos de forma significativamente maior em diferentes atividades quotidianas do que aqueles que viram filmes não-violentos.

E com base nestas evidências que a APA (American Psychological Association) justifica o monitorarnento das programações televisivas como o Estudo Nacional de Violência na Televisão (National Television Violence Study - NTVS) realizado pela Universidade de Santa Bárbara na Califórnia em conjunto com mais três univer sidades norte-americanas (SEPPA, 1997).

O fato dos meios de comunicação influenciarem no desenvolvimento de valores sem necessariamente expressá- los de uma fòrma direta é inegável. Neste sentido, torna-se importante venrificar a real quantidade de cenas violentas que se apresentam diluídas durante a programação televisiva diária e mais importante ainda, é conscientizar os adultos sobre a influência exercida por tais programas. Será que profecssores, pais, psicólogos e demais profissionais interessados, possuem tal informação? Será que estas informações não podem auxiliar na avaliação dos comportamentos de uma criança?

O NTVS realizou nos Estados Unidos, uma investigação a respeito da natureza dos programas exibidos por 23 canais durante cinco meses nos nos horários de 6:00h às 23:00h e observou que cerca de $57 \%$ dos programas exibem cenas que foram classificadas como violentas (NTVS, 1994, 1995).

A violência foi definida pelo estudo acima citado como: "Qualquer representação pública (aberta) do uso da força física - ou da ameaça crível de tal força - tencionando um prejuízo físico a um ou a um grupo de organismo. A violência também inclui certas representações de conseqüências fisicamente prejudiciais contra organismos, que ocorram como resultado de violência implícita” (NTVS, 1994, 1995, p.ix).

Após um estudo extensivo sobre o assunto, o trabalho citado (NTVS, 1994/1995) identificou três tipos de efeitos prejudiciais da exposição a programas com episódios violentos: I ) aprendizagem de comportamentos agressivos; 2) dessen-sibilização às conseqüências da violência; e 3) desenvolvimento do medo de ser vítima da violência.

Provavelmente estes efeitos são mais perceptíveis após algum tempo de exposição a programas deste gênero. Embora existam certos limites sociais para a expressão da agressividade, estudos longitudinais apontam algumas evidências de que a exposição a programas violentos influenciam comportamentos agressivos futuros. É possível que haja um efeito de acão simultânea, em que assistir programas violentos resulte em agressão que por sua vez, norteie a preferência por programas televisivos desta natureza (MOSER, 1991).

Estes achados são no mínimo preocupantes principalmente quando se pensa nos efeitos a médio e a longo prazo, visto que, provavelmente o maior público das programações televisivas são as crianças, pela sua maior disponibilidade de tempo. Apesar da pesquisa ter sido realizada nos Estados Unidos, algumas considerações do NTVS (1994/1995) merecem destaque, tais como: 1) em $73 \%$ de todas as cenas violentas, o criminoso não é punido; 2) as conseqüências negativas da violência não são retratadas na maioria dos casos; 3 ) em $25 \%$ da violência retratada, há o uso de armas de fogo; 4) canais de televisão a cabo apresentam maior índice de programas violentos (85\%); 5) os filmes são os programas que apresentam mais cenas realísticas de violência (85\%); 6) somente 4\% dos programas violentos utilizam fortes propagandas antiviolência; e 7) apenas 13\% dos programas com cenas violentas, mostram alternativas à violência ou como evitá-la.

Diante desse perfil, torna-se questionável o tipo de valor moral que é repassado nas entrelinhas de um programa televisivo, inclusive daqueles destinados ao público infantil. SEPA (1997), referindo-se aos resultados do NTVS (1994/1995), afirma que $40 \%$ da incidência de violência nos 
programas fazem parte de iniciativas de personagens idolatrados pelas crianças, tais como os heróis. Nesses casos os agressores não demonstram remorso e as vítimas parecem não sofrer tanto. Outra preocupação dos pesquisadores é que as crianças pequenas não distinguem a realidade da fantasia e com isto, podem imitar seus personagens prediletos, por achar que as consequiências não serão graves.

Não se encontrou nenhum estudo detalhado semelhante a este sobre a programação da televisão brasileira, mas é possível que ela não esteja tão longe da realidade americana, devido a grande influência exercida por esta.

Estas descobertas demonstram o quanto tanto a conduta dos adultos como a programação assistida, podem influenciar negativamente o comportamento da criança quando ela não está sendo monitorada por alguém que possa avaliar o que se mostra à criança na televisão. Isso ocorre em função da criança viver em processo de aprendizagem sem ter condições de avaliar o comportamento dos demais e por isso, está vulnerável às mais variadas influências.

Os trabalhos sobre a influência da televisão, como citado anteriormente, são muitos, e vários autores tentam fazer correlações entre os programas televisivos e atos futuros ligados à agressão. Entretanto, não há um veredicto sobre se a violência da televisão é a única responsável pelo comportamento agressivo infantil, mas considerando que a criança faz um registro constante dos acontecimentos a sua volta, ninguém gostaria que crianças jovens guardassem em sua memória cenas de violência.

Há três evidências, de acordo com o NTVS (1994/1995), sobre a preferência de crianças na escolha dos programas. Primeiro, as crianças cujos pais exercem influências nas escolhas de programas, são menos propensas a escolher programas rotulados como “problernáticos”. Segundo, as crianças que sentiram medo anteriormente ao assistir um programa, tendem a esquivar-se de programas que possuem advertências quanto ao conteúdo das cenas. Terceiro, as crianças que mais possuem comportamentos agressivos, demonstram mais interesse por programas que possuem advertências.

O fato de se ter referido quase que exclusivamente a programas não específicos ao público infantil, pode ser justificado por uma pesquisa realizada na década de 70 no Brasil (CAPARELLI, 1990), em que a preferência das crianças não era somente por programas infantis.

Na referida pesquisa, os seguintes programas lideravam a preferência infantil: novela, desenho, Jornal Nacional, Fantástico, Sitio do Pica- pau Amarelo, Os Trapalhões, Quarta Nobre e Mulher Maravilha. Isto demonstra que os programas considerados pelos adultos como adequados às crianças nem sempre atraem os telespectadores infantis.

Observa-se que os estudos preocupados com a influência dos programas televisivos sobre o comportamento infantil podem ser classificados em três categorias. Os experimentais, como aqueles apresentados por MOSER (1991), que procuram verificar a partir da exposição de cenas ou filmes a sua influência no comportamento. $\mathrm{O}$ centrado na análise da programação, como o realizado pelo NTVS (1994/ 1995), que parte do pressuposto de que esta programação influencia no comportamento dos telespectadores, e a partir disto faz um levantamento do que é exibido. Finalmente, uma outra forma de se analisar esta influência são os estudos centrados no comportamento do telespectador, que procuram verificar, a partir do relato verbal, o que é "filtrado" da programação que ele assiste. Embora os estudos experimentais tenham a comprovação mais contundente acerca da influência dos programas televisivos, todos os tipos de investigação têm a sua validade, pois atacam o problema (fenômeno) nas suas mais variadas frentes.

Este estudo é característico do centrado no telespectador, mais particularmente na criança, e propõe-se a fazer um levantamento das preferências de crianças pré-escolares de duas classes sociais, por programas televisivos. Procurou-se avaliar através das respostas, quais episódios são 'filtrados" por essas crianças e qual a sua natureza.

\section{MÉTODO}

\section{Sujeitos}

Foram sujeitos desta pesquisa dois grupos: a) 160 crianças (80 de cada sexo) de classe socioeconômica baixa, que frequentam creches ou escolas públicas; b) 190 crianças (95 de cada sexo) de classe socioeconômica média, que treqüentam escolas particulares. A idade dos sujeitos variou entre 60 e 81 meses, com a média de 68 meses. Todos são moradores do município de Belém - Pa.

\section{Ambiente}

A coleta de dados foi realizada em ambiente escolar nas salas de aula ou em pátios, dependendo da disponibilidade de espaço físico de cada escola.

\section{Material}

Foram utilizados questionários compostos de quatro perguntas, duas delas extensivas ao "por 
quê” para o primeiro grupo. No caso do segundo grupo, os questionários foram compostos de sete perguntas, sendo que quatro delas extensivas ao "por quê". O questionário continha também espaços para preenchimento de dados pessoais dos sujeitos.

\section{Procedimentos}

A coleta de dados foi realizada, por duas turmas de alunos da graduação do Curso de Psicologia da Universidade Federal do Pará obedecendo aos seguintes passos:

- Os alunos de Psicologia receberam informações sobre a pesquisa e foram instruídos sobre os procedimentos e o preenchimento do questionarão;

- Com um documento da Universidade, realizou-se um contato inicial com a escola, para explicar os objetivos do trabalho e solicitar permissão para realizar o mesmo;

- Os graduandos foram apresentados à professora, com a qual discutiu-se a melhor forma de se realizar as entrevistas;

- Escolhido o local mais adequado, as crianças foram chamadas individualmente pelo pesquisador, que sentava-se próximo a ela e depois de explicar o que seria feito, dava início à entrevista. Tudo que era verbalizado pela criança, foi anotado cursivamente, registrando-se o horário de início e do término da entrevista.

\section{RESULTADOS E DISCUSSÃO}

\section{Programas Preferidos}

Esta questão foi abordada em ambas as classes sociais, sendo permitida mais de uma resposta por criança, portanto, o número de respostas computadas foi de 192 para as crianças de classe média e 160 para as de classe baixa. Para se comparar os dois grupos sociais, verificou-se a frequência relativa das respostas, considerando-se o número de respostas computadas de cada grupo como a freqüência total (100\%). Com o intuito de facilitar a análise, todos os programas citados foram classificados em oito categorias, como segue:

1 - Desenho: inclui todos os desenhos animados de curta duração e que na maioria das vezes fazem parte dos programas infantis exibidos pelas emissoras de televisão. Ex: Pateta, Ursinhos Carinhosos, Tunder Cats, etc.

2 - Novela: refere-se aos programas que narram um romance e/ou aventuras que são divididos em capítulos e exibidos diariamente de segunda a sexta ou de segunda a sábado. Ex: Malhação, Por Amor, Chiquititas, etc.
3- Infantil: programa destinado ao público infantil, que pode ou não ter a presença de um apresentador que coordena as atividades desenvolvidas durante o mesmo. Ex: Eliana, Angélica, Chaves? Castelo Rá-tim-bum, Os Trapalhões, etc.

4- Filme: programa com duração média de duas horas, que possui uma estória verídica ou não, com início, meio e fim. Ex: Robocop, O boneco assassino, Batman, etc.

5- Esporte: todo e qualquer programa que se refere a notícias de acontecimentos esportivos ou a exibição de competição esportiva. Ex: Futebol, Globo Esporte, Corrida de Fórrnula 1, Basquete, etc.

6- Programa de auditório: inclui todos os programas destinados ao público adolescente ou adulto que possuem um animador e uma platéia. Ex: Domingo Legal, Programa Livre, Domingão do Faustão, etc.

7- Humorístico: inclui os programas de comédia destinados ao público adolescente e adulto. Ex: A praça é nossa, Casseta e Planeta, etc.

8 - Sem resposta: casos em que as crianças não souberam ou se recusaram a responder.

Os resultados demonstraram que as crianças de ambas as classes sociais assistem preferencialmente desenho animado (39\% da classe média e 51\% da classe baixa). Um fato interessante é que as crianças de classe média dividemse entre o desenho (39\%), a novela (26\%) e os programas infantis (32\%); enquanto que a maioria das crianças de classe baixa (51\%) escolheu desenho e em seguida os programas infantis (36\%). As demais categorias permaneceram abaixo de 5\% em ambas as classes sociais (Figura 1).

Figura 1: Preferência relativa de crianças de classe média $(n=192)$ e de classe baixa $(n=160)$ por tipos de programas televisivos

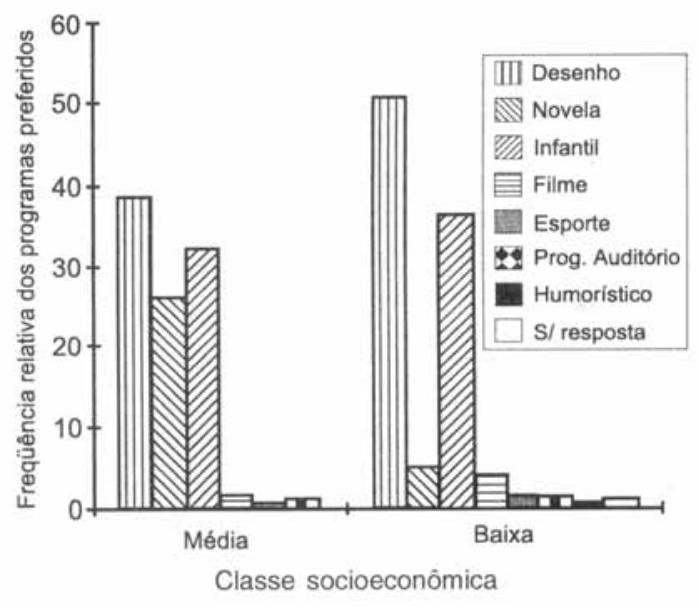


Nota-se, conforme figura 01 , que a diferença entre a preferência de desenhos e os programas infantis não é muito grande em ambos os grupos. A novela, que parece atrair $26 \%$ da preferência das crianças de classe média, não passa de $5 \%$ na opinião das crianças de classe baixa. Isso pode ser em função da realidade retratada nas novelas que é mais próxima das camadas sociais média para alta, do que das camadas de nível baixo e até mesmo porque as emissoras, com vistas a atrair este público, têm colocado crianças e temas relativos em seus enredos.

O fato do grande número de crianças assistirem a desenhos e programas infantis, diferentemente dos dados obtidos na década de 70 (CAPARELLI, 1990), pode ser um reflexo do surgimento de vários programas voltados ao público infantil a partir da década de 80, tais como os da Xuxa, Mara, Angélica, Vovó Mafalda, etc. E importante lembrar que a maioria dos desenhos assistidos pelas crianças são exibidos em programas dessa natureza.

\section{Desenho preferido}

Para fazer esta análise, selecionou-se somente as respostas cujos desenhos animados foram citados como programa preferido (freqüência total) e calculou-se a frequência relativa para cada sexo e grupo social em relação ao tipo de desenho mais assistido.
A variedade de desenhos citados pelas crianças de classe média foi 44 , enquanto as crianças de classe baixa citaram 29. Devido a essa grande variedade de desenhos, só serão mostrados nos gráficos os desenhos que foram citados mais de uma vez.

O número de respostas registradas para as crianças de classe média, foi de 44 para os meninos e 28 para as meninas, lembrando que este valor representou a frequência total para cada sexo. Conforme a figura 2, os meninos desta classe dividem-se quanto a sua preferência em dez tipos de desenhos, dentre os quais o Pateta e o Pato Donald são os preferidos com 9\%. As meninas citam mais frequentemente três tipos de desenhos, o Pateta (18\%), o Pernalonga (14\%) e o Scobydoo (11\%). Há também 14\% das meninas que não especificaram qual o tipo preferido nesta categoria.

Para as crianças de classe baixa o número de respostas registradas na categoria desenho foi de 48 para o sexo masculino e 34 para o feminino. Aqui também os meninos demonstraram maior tendência em escolher uma variedade de tipos de desenhos (sete tipos), diferentemente das meninas que se concentraram em quatro tipos, semelhante às de classe média. A diferença está nos desenhos citados, pois no caso dos meninos a preferência é maior pelo Máskara e Pica-Pau (ambos com 21\%), em seguida pelos Ursinhos Carinhosos (15\%) e Pernalonga (10\%), os demais fica-

Figura 2: Freqüência relativa da preferência de crianças de classe média por tipos de desenhos (respostas computadas: 44 meninos e 28 meninas)

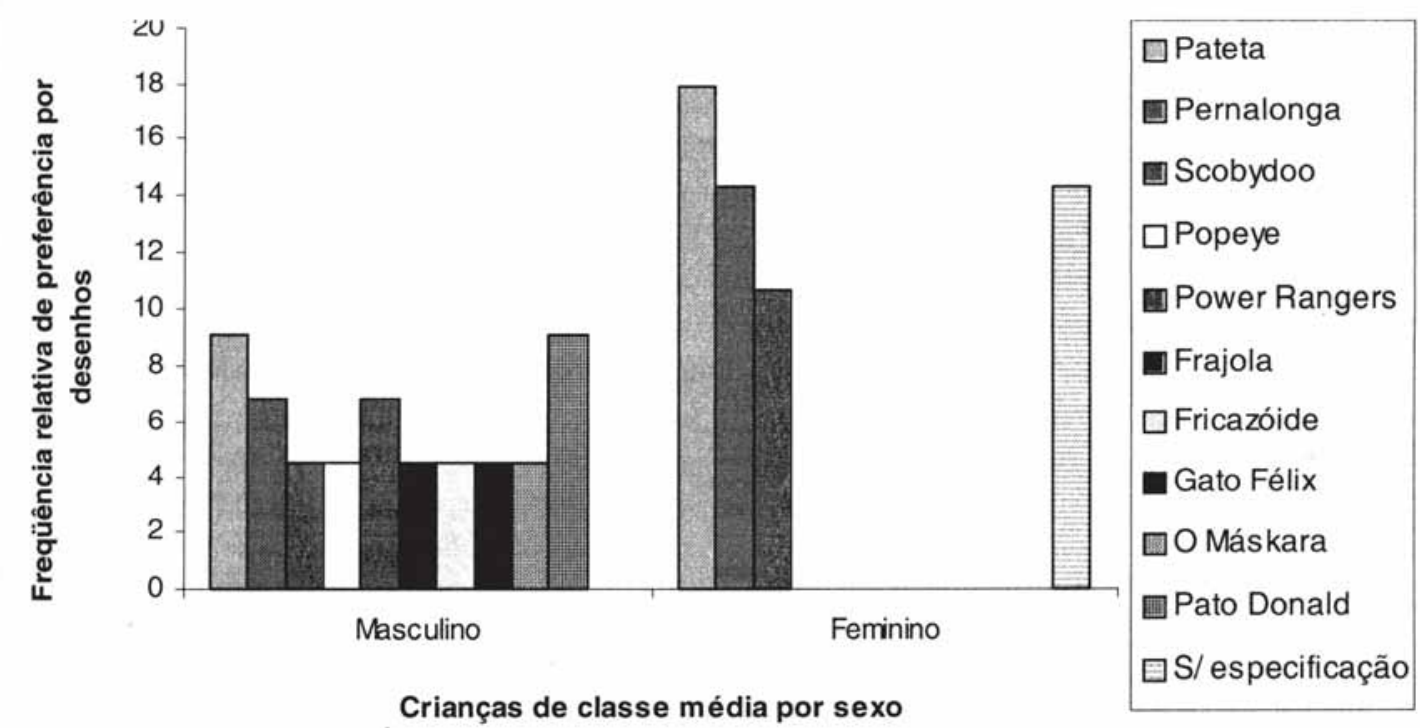


Figura 3: Freqüência relativa da preferência das crianças de classe baixa por tipos de desenhos (respostas computadas: 48 meninos e 34 meninas)

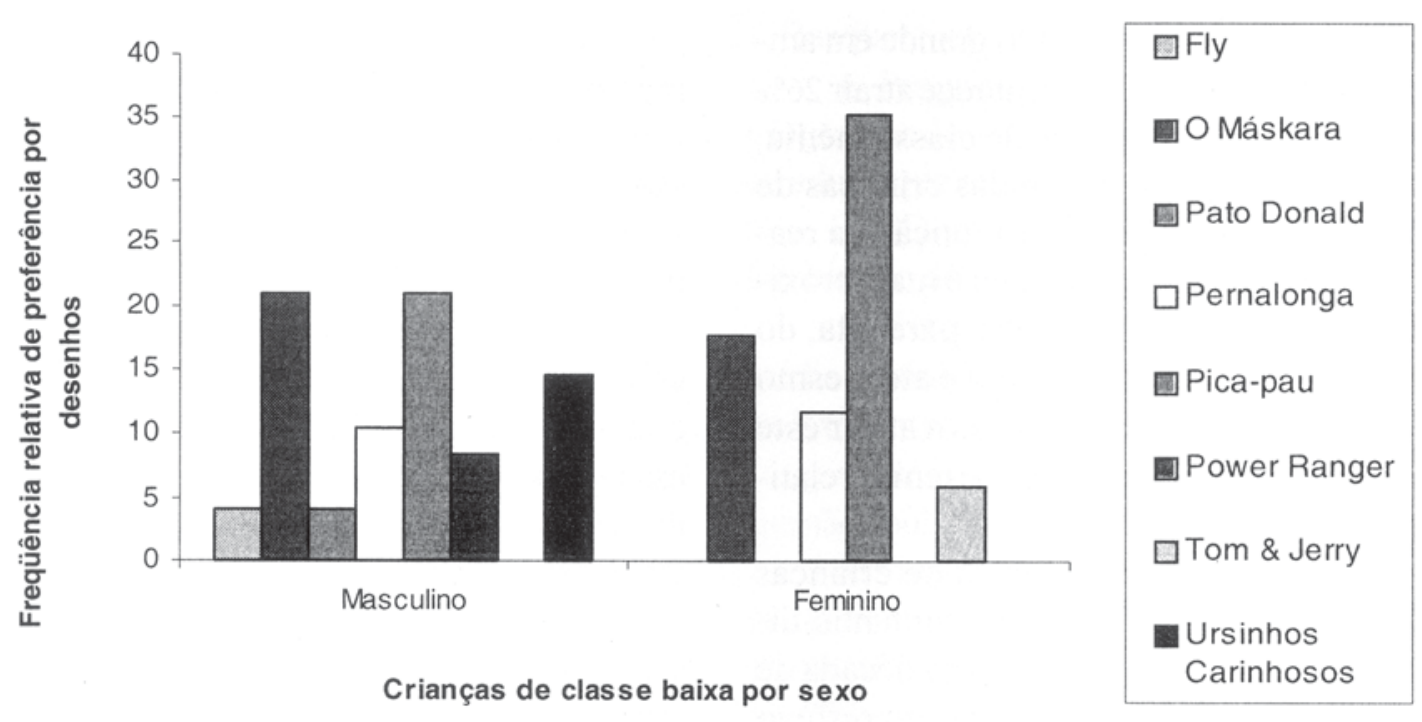

ram abaixo de $10 \%$. No caso das meninas, $35 \%$ prefere o desenho do Pica-Pau, 18\% o Máskara e $12 \%$ o Pernalonga (Figura 3).

A preferência de crianças de classe baixa de ambos os sexos por desenhos do Picapau foi observada também em um estudo de SANTOS (1996) realizado somente com crianças de classe baixa de Belém. No referido estudo, o segundo desenho mais citado pelos meninos foi Power Rangers, que ocorreu com menor frequência neste estudo; enquanto que, as meninas citaram com a mesma frequência o Pernalonga, Pato Donald e o Tom \& Jerry. Com a exceção do Pato Donald, todos os demais desenhos também foram citados pelas meninas de classe baixa do presente estudo.

Fazendo uma comparação entre as classes, nota-se que em função do número menor de variedade de desenhos citados pelas crianças de classe baixa, há maior número de respostas em comum sobre a preferência por tipos de desenhos. Um outro fato que chama a atenção é que a preferência da maioria das crianças de classe média é pelo desenho do Pateta e do Pernalonga, enquanto que as crianças de classe baixa preferem o Máskara e o PicaPau. Talvez esta preferência diferenciada possa ser esclarecida se as razões da escolha fossem analisadas. Entretanto, pode-se também inferir que crianças de classe média preferem desenhos cujo humor é tema principal e os personagens principais são animais. Por outro lado, crianças de classe baixa parecem preferir desenhos cuja versatilidade é mais localizada, pois o Pica-Pau é considerado um personagem versátil em suas relações (FUSARI, 1982; citado por SANTOS, 1996) e o Máskara usa a transformação como estratégia de ação.

\section{Relato de uma cena do Programa Preferido}

Esta é a questão central do presente trabalho, pois a descrição de uma parte do programa preferido pode dar um indício do que está sendo absorvido pelas crianças a partir da programação assistida.

Solicitou-se às crianças de ambas as classes sociais que contassem uma parte do programa que elas mais gostavam de assistir. As respostas foram muito variadas, mas foi possível agrupálas nas categorias a seguir:

1 - Afetivo altruísta: inclui relatos em que um personagem demonstra algum comportamento que expressa uma ligação afetuosa em relação a outro, algumas vezes com a intenção de auxiliálo. Ex: “...beijou ela”, “...fugiram juntos”, “...ele tinha que encontrar o tesouro para salvar o homem...", etc.

2 - Agressividade: são os relatos a respeito de comportamentos inadequados de um ou mais personagens com o intuito de causar danos a outrem. Ex: “...quando mata....”, “...quando bate no monstro...”, “...destruiu a mochila dele”, “...quando briga...”, etc. 
3 - Brincadeira: inclui relatos de atividades lúdicas ou jogos, como os de amarelinha ou pula corda. Ex: “...ele jogou bola...”, “...quando inventa brincadeiras...", "...para ver quem chega primeiro...”, etc.

4 - Suspense e espanto: inclui relatos de episódios em que há referência a enigmas a serem desvendados e/ou um personagem demonstra ficar assustado com alguém ou com algum acontecimento. Ex: “...descobre os mistérios...”, “....аpareceu um fantasma e a Maria gritou... “, “... tomou um susto”, “... assusta as amigas”, etc.

5 - Humor: inclui relatos de episódios cômicos e/ou que retratam travessuras dos personagens. Ex: “...são engraçados”, “...grudou chiclete na cadeira e sentou”, etc.

6 - Musical: refere-se a relatos de episódios em que um ou mais personagens desenvolvem atividades ligadas à música, com ou sem movimentos corporais rítmicos. Ex: “...quando cantam....dançam”, etc.

7 - Esperteza: episódios em que um personagem engana o outro em seu próprio favor. Ex: “...se disfarçou de mulher para enganar”, etc.

8 - Poderes mágicos: relatos de episódios em que um personagem usa de magia para transformar-se em outra pessoa, objeto ou animal. Ex: "quando ele ia virar peixe... “, “...se transformou mudando de cor...”, "...se transforma por causa dos poderes mágicos...”, etc.

9 - Dubialidade e s/ resposta: refere-se a casos em que a criança não respondeu e a todos os relatos que não possuíam um sentido lógico que permitisse compreensão do trecho e a classificação em outra categoria. Ex: “... quando estava indo...”, “...quando a velhinha aparece”, “...quando tem coelho", etc.

Fez-se uma comparação entre os sexos e os grupos, calculando-se a frequência relativa. A frequência total considerada baseou-se no número de crianças que optaram por “desenho”, sendo que para as crianças de classe média esse número foi de 44 para os meninos e 28 para as meninas. Na classe baixa, esses valores foram de 48 e 34 respectivamente.

Entre as crianças de classe média, nota-se que os episódios de “agressividade” foram citados com uma frequência maior, tendo sido referidos por $55 \%$ dos meninos e $25 \%$ das meninas. A segunda categoria mais frequente é "afetivo altruísta”, citado por $9 \%$ dos meninos e $21 \%$ das meninas. (Figura 4).

É importante salientar a preferência da grande maioria dos meninos de classe média pelas cenas de conteúdo agressivo apesar deles assistirem desenhos que as meninas também assistem, como o Pateta, Pernalonga e Scobydoo, mesmo que em proporções menores. Isto pode indicar que embora duas crianças tenham preferências pela mesma programação, as cenas que mais atraem sua atenção podem ser completamente diferentes uma da outra.

Figura 4: Freqüência relativa das categorias referente às cenas citadas pelas crianças de classe média (respostas computadas: 44 meninos e 28 meninas)

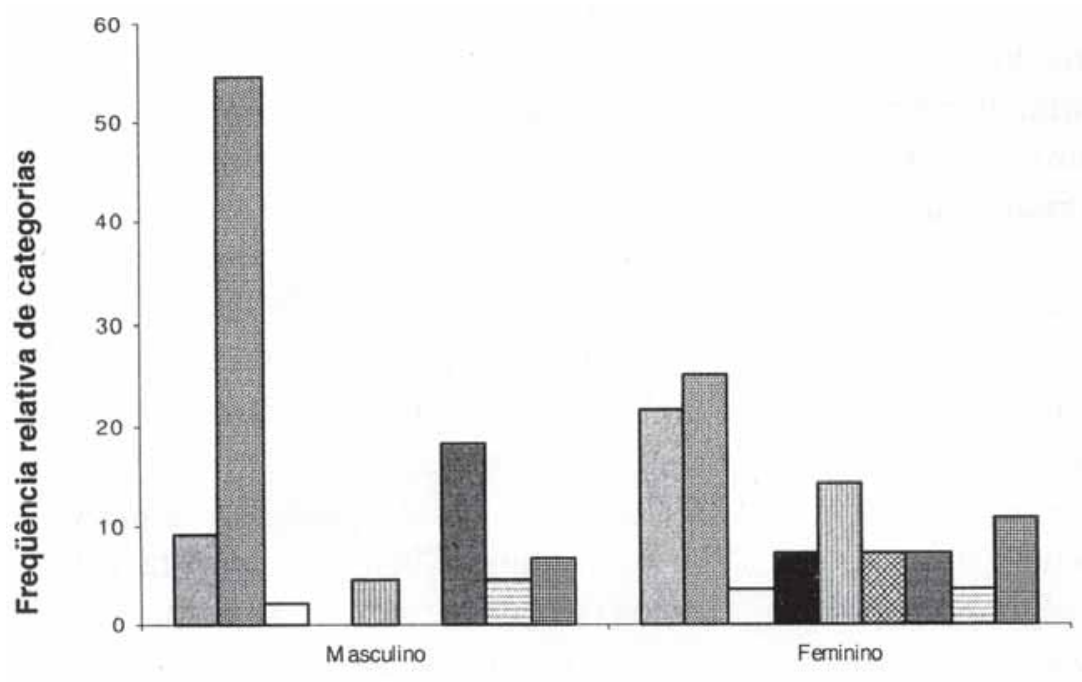

Crianças de classe média por sexo

$\square$ Afetivo altruista
$\square$ Agressividade
$\square$ Brincadeira
Suspense e
espanto
$\square$ Humor
Musical
$\square$ Poderes
mágicos
$\square$ Esperteza
$\square$ Dubialidade ou
S/ resposta


Figura 5: Freqüência relativa das categorias referente às cenas citadas pelas crianças de classe baixa (respostas computadas: 48 meninos e 34 meninas)

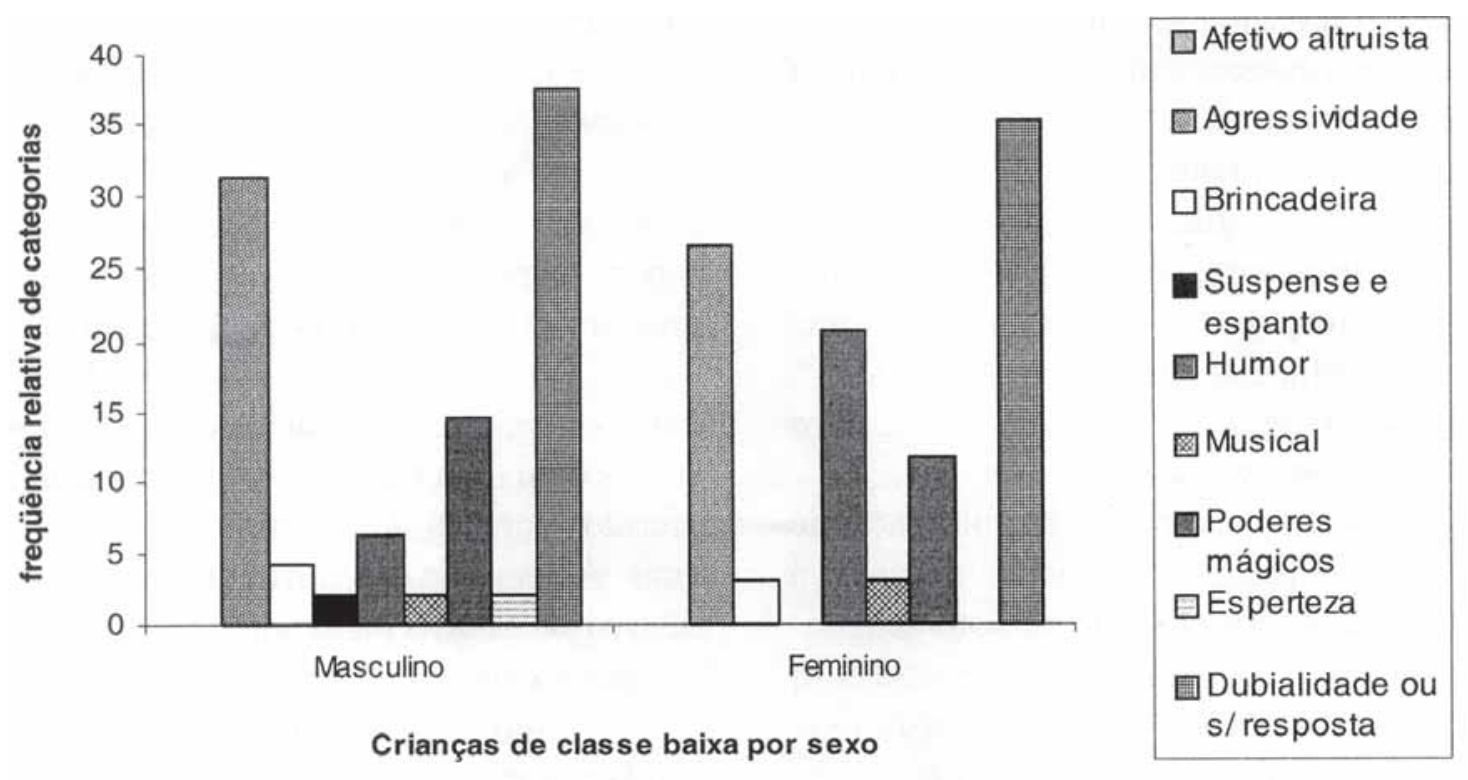

No caso das crianças de classe baixa a "dubialidade e s/ resposta" foi a categoria mais frequente tanto entre os meninos (38\%), quanto entre as meninas (35\%). A "agressividade" vem logo em seguida, tendo sido citada por $31 \%$ dos meninos e 26\% das meninas. Em relação a terceira categoria mais citada, há diferença entre os géneros, visto que $15 \%$ dos meninos citaram os episódios de “poderes mágicos” e 21\% das meninas, o "humor" (Figura 5).

Embora as crianças de classe baixa se refiram com uma frequência relativamente alta a episódios agressivos, como observado por SANTOS (1996), o que chama a atenção nesta questão é a alta frequência de crianças que não responderam ou cujas repostas eram dúbias. Também no estudo de SANTOS (1996), a maioria das meninas (77\%) não respondeu a esta questão. Segundo a autora talvez isso seja um indício de que as meninas estejam menos atentas ao conteúdo das estarias. Pode-se também supor que a tarefa de contar uma estória que já tenha visto ou ouvido anteriormente, assim como falar de suas preferências, não faça parte da rotina dessas crianças. Esta condição pode ser mantida pelos adultos de seu grupo social, que dificilmente procuram ouvir as crianças e estimulá-las a falar.

Quando se observa os dois grupos sociais como um todo, percebe-se que as crianças de classe média, apresentam uma freqüencia consideravelmente alta de relatos de cenas agressivas, há também igualmente, uma certa frequência de cenas afetivo altruístas. Por outro lado, as crianças de classe baixa citam com uma alta frequência os episódios agressivos, mas não relatam nenhum afetivo altruísta. Isto indica que as crianças de classe média "filtram" ambos os tipos de episódios, o que sugere que elas tenham maior probabilidade de comportar-se nesses dois sentidos do que as crianças de classe baixa.

\section{Programas que mais desagradam as crianças}

Em relação à esta questão, foram permitidas mais de uma resposta por sujeito. Portanto, registrouse 268 respostas para as crianças de classe média e 160 respostas para as de classe baixa. Esses valores foram considerados como a frequência total para os respectivos grupos.

Essa questão proporcionou a descoberta de alguns fatos curiosos que podem ser observados na figura 6. O desenho está entre as três categorias mais citadas em ambos as classes sociais. Isso é contraditório com as respostas obtidas sobre programas preferidos, onde o desenho foi a categoria mais citada. Talvez em função das crianças assistirem muitos desenhos, elas acabem selecionando os mais atraentes e menos atraentes dentro de uma mesma categoria de programas. 
Figura 6: Freqüência relativa dos programas que mais desagradam o público infantil de classe média $(\mathrm{N}=268)$ e de classe baixa $(\mathrm{N}=160)$
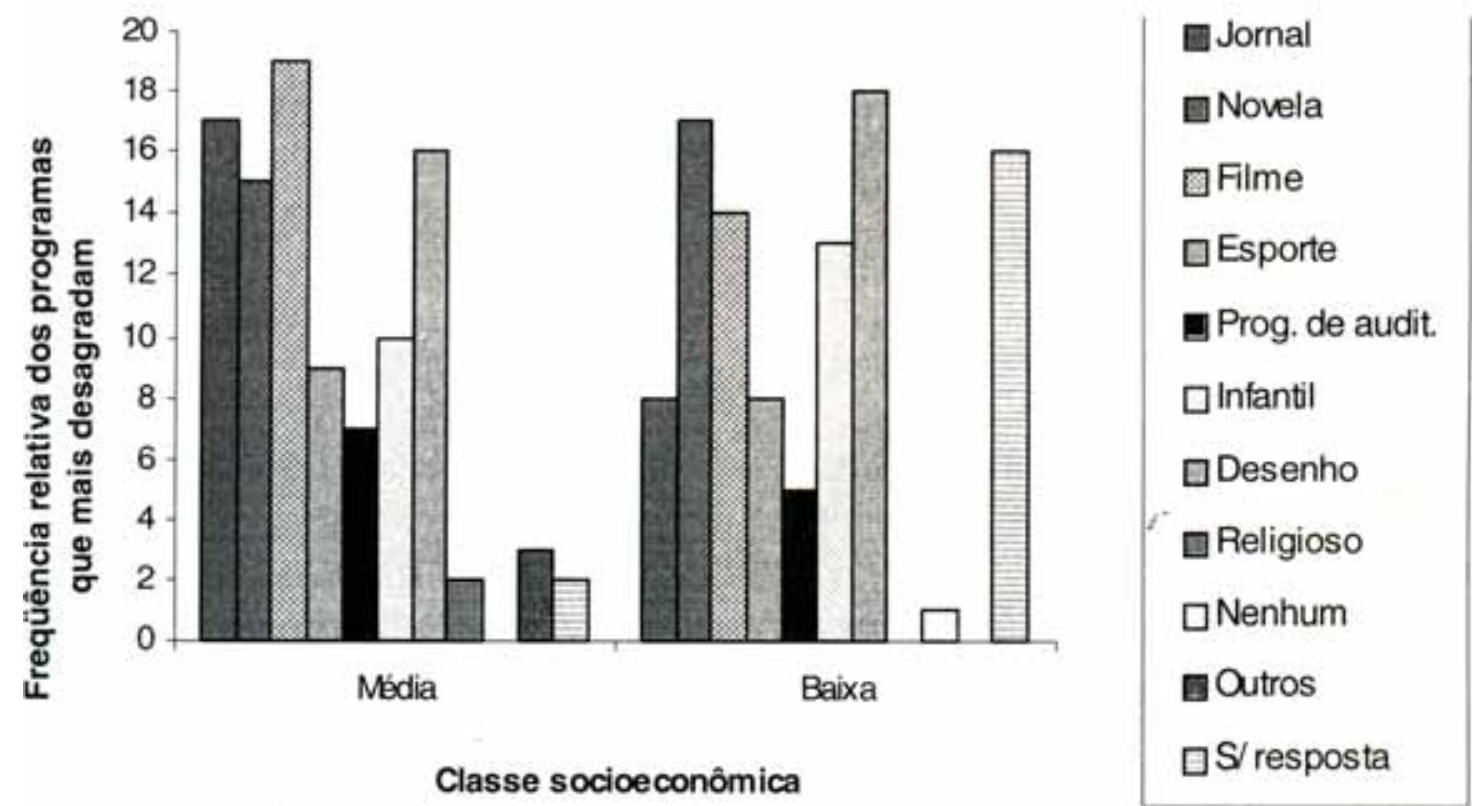

Outro falo interessante é a rejeição por novelas, que também demonstrou-se alta em ambas as classes, pois na classe média, a novela foi a terceira categoria mais preferida. Essa aparente contradição pode ser devida ao fato de que as crianças optem por assistir determinados tipos de novelas, mais voltados ao público infantil. Como a maioria das novelas não possui essa característica, as crianças assistem assiduamente uma novela específica e rejeitam as demais. Nesses dois casos (desenho e novela), a alta frequência não indica necessariamente uma menor preferência, mas uma alta seletividade dentro dessas categorias.

\section{CONCLUSÃO}

Diferentemente do que foi indicado por CAPARELLI (1990), as crianças de ambas as classes sociais assistem mais programas infantis. Infelizmente não se tem conhecimento de pesquisas longitudinais no Brasil, tal como o realizado pelo NTVS (1994/1995), que procurem relacionarapreferênciade crianças por programas televisivos e os seus comportamentos futuros. Uma pesquisa de tal dimensão seria muito interessante para uma melhor investigação sobre o assunto.
Apesar da presente pesquisa ter investigado a preferência de crianças de duas classes sociais em apenas uma capital brasileira, os resultados demonstraram que há algumas diferenças e semelhanças que merecem destaque, tais como:

a) O fato das crianças serem fiéis a determinados programas.

b) A grande preferência por desenhos animados e programas infantis.

c) Uma maior variedade de tipos de desenhos citados pelos meninos do que pelas meninas.

d) A dificuldade das crianças de classe baixa em explicar suas escolhas, que sugere um repertório verbal mais restrito quando comparadas às de classe média.

e) $\mathrm{O}$ fato de crianças de ambas as classes sociais relatarem episódios agressivos, com uma grande frequência.

E preciso avaliar a metodologia utilizada, no caso a entrevista, que pode ter favore cido as crianças de classe média, contrastando com a visível dificuldade das crianças de classe baixa em relatar os episódios de seus programas preferidos, fato que pode ter interferido nos resultados.

Pode ser que os resultados obtidos neste estudo sejam diferentes das de outras re giões do país, como um reflexo das características próprias 
das emissoras do local, dos hábitos familiares e da influência da comunidade local, sendo interessante realizar um levantamento dessa natureza em outras localidados, não só em outras capitais, mas também no interior do estado. Possivelmente uma comparação entre áreas urbanas e rurais levante discussões interessantes.

Independentemente dessas possíveis diferenças, um falo importante que deve sei lembrado a partir da constatação do grande número de episódios agressivos citados, é o alerta de que a televisão não deve ser utilizada como uma "babá eletrônica”, ou seja, os pais não devem ver a programação televisiva como instrumento de "distração de crianças”. Deve-se lembrar também que a percepção da criança pode variar em função das orientações que ela recebe enquanto assiste os programas, daí a importância do monitoramento de um adulto nesse momento.

\section{A GRADECIMENTOS}

Aos alunos de graduação em Psicologia dos semestre 2/96 e 2/97 pelo auxílio na coleta de dados; à bolsista Mônica Coelho; a direção e ao corpo técnico de todas as escolas do município de Belém que permitiram a realização desta pesquisa; e ao prof. Dr. Stephen Ferrari pela tradução do resumo para o inglês.

\begin{abstract}
There is good evidence of the negative effects of television programs with scenes of violence on the behavior of children; therefore, it is important to establish what they remember from the programs they watch. With this in mind, the viewpoint of the infant viewer on television programs was investigated through a questionnaire and individual interviews of 350 five- and sixyear old children from lower (160) and middle (190) socio-economic classes. The results indicate that aggressive episodes are among the most preferred by children of both sexes and from both social groups. It was also noted that lower-class children have difficulty in making verbal reports. This scenario demonstrates that adults should monitor the programs watched by children and also that the methods used may have favored middle class children in comparison with those from the lower social class.
\end{abstract}

Key-words: pre-school children; television programs; aggression.

\section{REFERÊNCIAS BIBLIOGRÁFICAS}

CAPARELLI, S. Televisao, programas infantis e a criança. In: ZILBERMAN, R. (org.). A proução cultural para a criança. $4^{\mathrm{a}}$ ed. Porto Alegre, MercadoAberto, 1990.

GOOD TELEVISION HABITS. Helping your child get ready for school. Texto disponível na Internet http:/ /www. ed.gov/pubs/parents/ GetReadyForSchool/TVHabits.html[1998, may 14].

NATIONAL TELEVISION VIOLENCE STUDY Summary of findings and recommendations. Mediascope, 1994/1995. (Relatorio técnico).
MOSER, G. A agressão. São Paulo, Ática, 1991. MUSSEN, P. H.; CONGER, J. J.; KAGAN, J.; HUSTON, A. C. Identidade e desenvolvimento social. In: Desenvolvimento e personalidade da criança. 2a ed. Sao Paulo, Harbra, 1998.

SANTOS, L. P. Preferência de crianças por programas televisivos. Belém, 1996. [Trabalho de Conclusão de Curso (Graduação em Psicologia) - Universidade Federal do Pará].

SEPPA, N. Children's TV remains steeped in violence. American Psychological Association, 1997. Texto disponpível na Internet. http:// www.apa.org/ monitor/^Jun97/tv.html [1998, may 14]. 